\title{
Industrial Revolution 4.0 And Global Citizenship Education In Vietnam Today
}

\author{
Nguyen Thi Toan \\ Hanoi Metropolitan University - Vietnam \\ Le Thi Quynh Nga \\ The Vietnam National Institute of Educational Sciences - Vietnam
}

\begin{abstract}
Beginning with analyzing the nature and effects of the Industrial Revolution 4.0 to the contemporary world, the article shows the impact of this revolution on the formation and development of the generation of global citizens. Thereby, the global citizenship education in Vietnam today which is clarified and reflected in the renovation of high school education and higher education.
\end{abstract}

Keywords: Industrial Revolution 4.0; Global citizens; Global citizenship education; Education innovation

\section{INTRODUCTION}

The world is experiencing the Industrial Revolution 4.0 (IR4.0) - a revolution redrawing the world map, an inevitable step of the automation of production, internet connection and digitization. This revolution has a double impact in the direction of polarization, resulting in a strong change on all subjects and areas of life which not only creates a number of favorable opportunities but also poses many difficulties and challenges for the development of countries around the world. Educating the generation of global citizens who are capable of taking advantage of opportunities, overcoming challenges, bridging and motivating the development of nations and peoples is an indispensable requirement of the modern time.

\section{LITERATURE REVIEW}

There have been many studies on IR4.0 as well as the relationship between IR 4.0 and Global citizens.

In the article Education 4.0: New challenge of learning [7], Puncreobutr,V. Has affirmed that it is vital for the youth to keep pace with changes in order to be competitive in this 4.0 era. The learner needs to have the skills and abilities to respond to the current social changes. This is a new challenge to redefine the new Education 4.0, to identify the intelligent people, who are creative and innovative.

Yanzi, H., Hidayat, O. T., Mentari, A., \& Budimansyah, D. has emphasized in the article Global Citizens Awareness through Digital Literacy in the Fourth Industrial Revolution: A Review of the Literature [10] that digital literacy is an important implication to collaborate and communicate with global digital networks that enable every individual to be aware of being an active and participatory citizen of world issues without losing identity.

Mannion, G., Biesta, G., Priestley, M., \& Ross, H. have called for curricula in schools and higher education in the 4.0 era to include a global dimension and education for global citizenship that will prepare students for life in a global society and work in a global economy in their research The global dimension in education and education for global citizenship: Genealogy and critique [4]. In their opinion, curricula in schools and higher education should bring three 
educational traditions together: environmental education, development education and citizenship education.

The article The Fourth Industrial Revolution and the role and mission of universities of science and technology in training high-quality human resources by Duc Tran Khanh [2] has affirmed that IR4.0 with the main trend of digitization which is based on the achievements of modern science and technology, has rapidly changed all aspects of the socio-economic life of all nations. In that process, the role and position of universities has increasingly beenappreciated so that they can really become the pioneer in the development process of this revolution.

Vi Nguyen Huy and Giao Nguyen Long with their article The adaptation of Vietnamese education to the impact of the Industrial Revolution 4.0 [8] have shown that changes in teaching technology and new educational trends need to be analyzed based on the approach that the role of schools should be considered as a learning ecosystem through the application of specific technology of IR4.0, from which to propose some development orientations for education in the future.

Some authors concentrate on different aspects of global citizenship education through specific subjects such as: Ha Nguyen Thi Viet with Global Citizenship Education in Civic Education in Secondary schools (New education curriculum) [3]; Dien Bui Thi with An approach to global citizenship education in Literature [1]; Nga Nguyen Tuyet and Lien Nguyen Hong with Global Citizenship Education through History and Geography in Primary schools [6] .ect. However, there has not been any systematic work on IR4.0 and Global citizenship education in Vietnam today.

On the basis of selective inheritance of previous research achievements, with a systematic approach, this paper generalizes the IR 4.0 and Global citizenship education, thereby clarifying the need and direction for educational innovation in Vietnam for Global citizenship education in order to meet the requirements of IR 4.0.

\section{AN OVERVIEW OF INDUSTRIAL REVOLUTION 4.0 AND GLOBAL CITIZEN IN INDUSTRIAL REVOLUTION 4.0}

\section{Industrial Revolution 4.0 - a qualitative change in the new era What is Industrial Revolution 4.0?}

In human history, there have been significant breakthroughs marking new eras of history, typically industrial revolutions in early modern and modern periods.

The first industrial revolution took place between the mid-18 ${ }^{\text {th }}$ century and the mid-19th century, starting from the textile industry in England. England, which was the pioneer of the revolution with the invention of the steam engine, became the world's factory. This revolutionalso shaped the role of capitalism on the worldwide scale, changing the vocational structure in capitalist countries.

The second industrial revolution occurred in the late $19^{\text {th }}$ century and the early $20^{\text {th }}$ century. With the invention of electricity and new energy sources, America rose took the lead in this revolution. 
The third one occurred in the second half of the $20^{\text {th }}$ century, mainly in the field of technology, so it was identified by its own name: scientific and technological revolution. It was a revolution based on electronics and information technology with the advent of computers and the Internet, profoundly and comprehensively changing social life, from economics to politics and culture.

In the early years of the 21th century, the Fourth Industrial Revolution (IR4.0) was born on the basis of the achievements of the Third Industrial Revolution and the latest achievements of science, quickly become a topical issue all over the world. The term "Industry 4.0" was first used at the Hannover Fair in Germany. This is the initial concept of IR4.0. After only 4 years, this concept had spread all over the world. In some other countries, IR4.0 was called by other names such as IP industry, smart manufacturing, digital production ... Despite that variation in name, the connotation of the concept was basically similar to a digital revolution which transformed the entire real world into a digital world through modern technologies.

Outstanding achievements of IR4.0 are: 1/ Internet of Things (IoT) technology with the trend of combining new sensor technology, big data analysis, cloud computing and IoT connectivity to enhance the development of automated machines and smart production systems; 2/ 3D Printing technology allows printing by non-traditional methods, thereby skipping intermediate stages and reducing production costs; 3/ Modern biotechnology helps us quickly decode genomes, learn more about genetic codes, edit gene codes to cure genetic diseases and create new varieties of plants adapting to different environment; 4/ Nanotechnology and new materials allow the creation and wide application of new material structures; 5 / Artificial Intelligence (AI) and cybernetics have a great development which allows people to remotely control everything, which is not limited to space and time, to interact faster, better and more accurately.

IR4.0 inherited the achievements of the Third Industrial Revolution. However, it is not an extension of that revolution but a qualitative change in the following aspects:

- Exponential progress thanks to the Internet system. The main factor determining the progress is expressed through how society accepts technology innovation. The speed of increase in quantity (level of growth, the increase in scale), popularity and rapid spread have affirmed the superiority of IR4.0;

- Robot technology turns to a new page in which it can replace people in many stages of the production line;

- Atomically precise manufacturing technology can completely remove scrap during the production process;

- Technology connects between the real and virtual worlds, people and robots, intelligence and artificial intelligence products, opening a new era in connection services (linking between people and people, people and objects, objects and objects ...)

\section{The impacts of industrial revolution 4.0 on the contemporary world}

The IR4.0 has brought the world into a new era of economy: knowledge economy, digitization, automation and globalization. Klaus Schwab - Executive chairman of the World Economic Forum said: "We stand on the brink of a technological revolution that will fundamentally alter the way we live, work and relate to one another. In its scale, scope and complexity, the transformation will be unlike anything humankind has experienced before" [11]. This revolution has profound and comprehensive impacts on the modern world. 
In terms of productive forces: During the IR4.0, with the advent of knowledge economy (knowledge economy), the productive forces of mankind have changed in terms of quality. Science and technology, knowledge penetrated into every element of the productive forces, quickly became a direct productive force, enhanced productivity and creativity, promoted strong economic development, greatly benefited consumers, thereby leading to all changes in society. However, the risk of unemployment caused by robotization also seriously warned employees to constantly better themselves to win in the fierce competition between people and robots.

Regarding the relations of production: 1. In IR4.0, intellectual property right takes the priority; those who own intellectual property capital, scientific and technological capital, especially information technology have increasingly played an significant role in society; 2 . With the IoT, machines are connected to each other in the automatic operation of production lines so managers have to constantly innovate the way of organization and economic management, conduct market research, employ information technology in digitizing the entire business process; 3 . With the strong development of production, people's income will increase, inevitably leading to the widening gap between the rich and the poor. Besides those who quickly become rich thanks to great intellectual and financial capital, there will be unemployed low-skilled workers. To become an GC is to get rid of inequality in the new society which is full of disadvantages for low-skilled workers.

Regarding the superstructure: IR4.0 provides new trends for e-government development. Thanks to the power of new technology with modern equipment, the national capacity of management, administration and social control will increase. At the same time, there will be a number of opportunities for citizens to actively and effectively participate in political and social issues. Society will be increasingly open, transparent and more democratic, from which civil rights will be guaranteed more.

In conclusion, IR4.0 has been increasingly strong. It has had a double impact with the polarization trend to all areas of human life in general, to every human being in particular. Basically, people will enjoy fruitful achievements: a more sufficient, leisure and spiritually abundant life. However, from its depth, this IR also warns about the risk of rich and poor division, human robotization, private secrets violation, changes in sex reproduction, degradation of traditional values, loss of national cultural identity in the process of globalization, etc. In the current context, in order not to be left behind in the process of IR4.0, we should accurately identify those impacts and establishcommon values in order to contribute to choosingappropriate solutions for this IR to become a great opportunity for humankind. One of those solutions is Global citizenship education.

\section{Global citizens - the product of industrial revolution 4.0 What is a Global citizen?}

The term "Global citizen" (or World Citizen) only appeared in Vietnam at the beginning of the 21st century. So far, there has not been a complete and officially recognized definition of this term. According to Wikipedia, Global citizen is "people who live and work in many different countries ... who can have one or more nationalities" [12].

In order to become a Global citizen, the following basic competencies are required:

1. Having strong professional competence, meeting the requirements of modern science and technology; 
2. Having a deep understanding of cultures over the world;

3. Being capable of using foreign languages to confidently communicate with the world;

4. Being capable of using information technology to serve learning, research and work;

5. Being capabe of thinking independently, work proactively and independently in life;

6. Having the capacity of rhetoric, debate, cooperation and collective work.

With these capabilities, a Global citizen can travel to many places ("Green Passport around the world"), confidently communicate with many people around the world; choose to work in many different countries with international income.

In addition to the above capabilities, to overcome the reverse of IR4.0 and globalization, Global citizen also needs other important qualities such as cultural tolerance, equality, love, respect for people and living environment, active participation in solving global problems (wars, terrorism, epidemics, environmental pollution, exhaustion of natural resources) .vv In short, global citizens are those who have essential qualities and competencies to meet the requirements of the Industrial Revolution 4.0, who can work in many different countries with international income level, contributing to the general development of the world.

According to Oxfam, in order to become a Global citizen, young people need to equip themselves with essential knowledge, understanding, skills and values to bring happiness to themselves and to the community, contributing to building national and humankind benefits [15]. Global citizen needs to know about different cultures, explore the world values which reflect moral ideal underpining human existence such as human rights, pluralism religion, environmental protection, poverty reduction, sustainable economic growth, the elimination of weapons of mass destruction, prevention and cessation of conflicts between nations, humanitarian assistance and the preservation of the world cultural diversity, etc. Global citizens will not deny their national identities (loyalty to the country, ethnicity and political beliefs ...) which identify who they are on the global map. However, living in a globalized world, Global citizens needs one more responsibility also - the responsibility of being a member of a global community of people who share a global identity to accept and actively participate in protecting the world.

\section{The cause of formation and development of global citizens}

The process of formation and development of Global citizen generation results from the development of scientific and technological revolution, particularly the IR 4.0 which leads to:

1. The formation of multinational companies: The development of science and technology, the process of globalization has formed multinational companies which have branches and representative offices across continents. The first Global citizens have been formed by the management team in these branches and offices.

2. The demand to attract gray matter of countries: Due to the development of science and technology, the world has increasingly been abundant with unskilled labor butscarce of high-quality labor. Governments in many countries have a number of preferential policies to invite and naturalize entrepreneurs, scientists and doctoral graduates at prestigious universities. This team has become Global citizens due to the ability to live and work in many parts of the world. Today, the achievements of IR 4.0 help replace the brain drain from poor countries to rich countries by the circulation 
of gray matter, or gray matter chains. That is also the reason leading to the outbreak of Global citizen generation among young people.

3. The need to survive and develop in more favorable human environments: The development of science and technology also promotes the need to live and work in more favorable environments. Qualified people will have the opportunity to choose a country that meets their needs. At that time, they have nationalities of their homeland and their new residence.

4. The formation of global identity: Achievements of modern information technology, communication and transportation contribute significantly to the formation of global identity. These achievements help enhance the ability to connect between individuals and the rest of the world through the Internet; effectively participate in the global economy; empathize with disasters in other countries; Easily travel and visit other parts of the world. Living in a globalized world, crossing the tangible or invisible boundary between their country and the world or between regions of the world, gradually people will have not only the traditional identity from where they were born, but also the identity of the world community - the identity of Global citizens.

5. Global issues to solve: The dark side of science and technology poses global challenges. When people are aware of their role in global identity, they will actively participate in activities that solve global problems for the common good of humanity. At that time, even though they have not traveled to many places in the world or they have only one nationality, they have qualities of a Global citizen.

\section{The importance of Global citizenship}

First of all, when being Global citizens, those citizens will enjoy the good results of IR4.0: High income helps them to meet the rich material and spiritual needs; traveling around the world and having good foreign language skills help them communicate with many people in countries to broaden their horizons, improve their skills; having more than one nationality makes them enjoy more civil rights, helping them both retain the national cultural identity and foster more knowledge about other national cultures.

On the other hand, Global citizen can greatly benefit society thanks to the amount of knowledge and experience they have accumulated while living and working in different countries and cultures. Global citizens with their experience, knowledge and language competency will become the bridges between countries in terms of economy, politics, culture, science and technology, contributing to developing the economy, solving global problems, establishing peaceful politics, enriching the colorful cultural garden of mankind, building a peaceful and sustainably developed world. Many Global citizens who choose to live in developed countries send remittances to the country, support building the business relationships, scientific and technological and educational cooperation.

Due to the importance and great influence of Global citizens to the world, Global Citizen is headquartered in New York, with offices in Canada, South Africa, Australia, Germany, and the United Kingdom. The organization was co-founded by Hugh Evans, Simon Moss, Wei Soo in 2008. The Global Citizen platform was co-founded with Ryan Gall and Riot House in 2012 [13]. 
In response to the challenges of IR4.0 and the process of globalization, UNESCO developed the Global Citizenship Education Program (GCEP). It aims to instil in learners the values, attitudes and behaviours that support responsible global citizenship: creativity, innovation, and commitment to peace, human rights and sustainable development. UNESCO's work in this area is grounded in its own Constitution which aims to 'build peace in the minds of men and women,' the Universal Declaration of Human Rights, the Education 2030 Agenda and Framework for Action, notably Target 4.7 of the Sustainable Development Agenda, the Recommendation concerning Education for International Understanding, Co-operation and Peace and Education relating to Human Rights and Fundamental Freedoms (1974), and the World Programme for Human Rights Education (2005-ongoing).

UNESCO collaborates with an extensive global network to disseminate GCED including its own Category 1 institutes, other UN agencies and inter-governmental organizations, including regional organizations, most notably: the UNESCO Mahatma Gandhi Institute of Education for Peace and Sustainable Development (MGIEP), the International Institute for Capacity Building in Africa (IICBA), the UNESCO Institute for Statistic (UIS), the Asia-Pacific Centre of Education for International Understanding (APCIEU), the UNESCO Associated Schools Project Network (ASPNet) and UNITWIN/UNESCO Chairs [14]

\section{VIETNAM WITH GLOBAL CITIZENSHIP EDUCATION IN THE 4.0 INDUSTRIAL REVOLUTION}

\section{Global citizenship education - an indispensable requirement for Vietnam's education today}

In industrial revolutions, countries that seize the opportunity and turn that opportunity into reality will quickly develop and vice versa. IR4.0 will change the whole world in the very near future. Robots, internet of things, automation ... will drastically change the labor market, causing some jobs to disappear in a few years. However, robots, automation and artificial intelligence are still not capable of solving complicated problems which require multidisciplinary, multi-dimensional and even multicultural understanding capacity. Therefore, it is important to equip learners with necessary skills to adapt to the rapid changes of the work environment and labor market. Having been deeply aware of opportunities and challenges of IR4.0, the education of advanced countries in the world has updated achievements of this revolution to train the Global citizen generation, meeting the requirements of sustainable development.

Over the past time, despite certain achievements, the quality of Vietnamese education has not met the requirements set out. Resolution 29 of the Communist Party said, Vietnam Education still "emphasizes on theory, makes light of practice; lacks the link between training and scientific research, business production and labor market needs; haven't focused properly on ethical education, lifestyle and working skills; methods of education, testing and evaluation are outdated and impractical also ..." [9]. Weaknesses in education lead to the weaknesses of human resources. Vietnam is in a period called "golden population" with approximately $70 \%$ of people of working age but there is a shortage of highly skilled labor. Even qualified workers are still weak in practical skills, foreign language and the adaptability in the industrial environment. The graduates are still inflexible, passive, lack soft skills and fail to meet the requirements of employers. The high quality human resources market in Vietnam enterprises has to fiercely compete with qualified foreigners working in Vietnam. 
The limitations of human resources is the main factor affecting the competitiveness of the economy. It can be affirmed that Vietnam education has not taken advantage of IR4.0 achievements. The Global citizen generation has not been properly trained to participate in the global value chain as well as enhance our position in that chain. Becoming a Global citizen should be the goal of the young generation. To do so, they need to discover their own potential, expand their horizons and think globally. They need to be trained in an international standard environment also. Therefore, fundamental and comprehensive innovation of education - training is an indispensable requirement to improve the quality of human resources, to equip future generations with a strong cultural foundation and a high level of adaptability to deal with all fluctuations of the world - Global citizen competency, helping Vietnam narrow the development gap and integrate more deeply and effectively into the world.

\section{Innovations in Global citizenship education in Vietnam today Innovations in general education}

The spirit of Global citizenship education is clearly reflected in the new general education curriculum 2018, from the perspective of program development, goals, education plans, content, to the educational method and evaluation of educational outcomes. The curriculum aims to develop qualities and competencies of learners, createsa learningand training environment in which students can developphysically and mentally; focuses on practical skills, creativity, adaptation and international integration. The program also concentrates on conforming to the characteristics of Vietnamese people, culture, traditional values and the common values of humanity embodied in UNESCO's educational philosophy; create equal opportunities for students' right to study, develop and participate; to be cared, heard and respected; builds the foundation for a humane, sustainably developed and prosperious society. The program has concretized the goals of general education curriculum in order to help students master general knowledge, effectively apply knowledge and skills learned into their life as well as self-study for life. It also guides them in their vocational choice, helps them build and develop harmoniously social relationships, develop their personality and enrich their spiritual life, thereby they can have a meaningful life and contribute positively to the development of the country. Along with that, we also review and eliminate duplicate educational content as well as develop integrated content and topics; increase the use of active education methods, organize teaching and learning activities to develop learners' competencies; focus on testing and assessing the ability to apply the knowledge learned into practice, promote life skills education. Innovating and enhancing the quality of foreign language and information technology teaching with the direction of standardization and practicality, ensuring that the practical capacity of learners has been taken into consideration.

Table 1: Target requirements on main qualities and competencies of student

\begin{tabular}{|c|c|c|}
\hline $\begin{array}{c}\text { Main qualities of } \\
\text { student }\end{array}$ & $\begin{array}{l}\text { General competencies of } \\
\text { student }\end{array}$ & Specific competencies of student \\
\hline $\begin{array}{l}\text { 1. Patriotism } \\
\text { 2. Compassionate } \\
\text { 3. Diligence } \\
\text { 4. Honesty } \\
\text { 5. Responsibility }\end{array}$ & $\begin{array}{l}\text { 1. Self control and } \\
\text { Independent learning } \\
\text { competencies } \\
\text { 2. Communication and } \\
\text { Colaboration competencies } \\
\text { 3. Problem-solving and } \\
\text { Creative competencies }\end{array}$ & $\begin{array}{l}\text { 1. Language competence } \\
\text { 2. Mathematics competence } \\
\text { 3. Scientific competence } \\
\text { 4. Technological competence } \\
\text { 5. Computing competence } \\
\text { 6. Aesthetic competence } \\
\text { 7. Physical competence }\end{array}$ \\
\hline
\end{tabular}

(Source: Ministry of Education and Training) 
According to the general education curriculum of Ministry of Education and Training [5], five qualities a student is expected to have include patriotism, compassionate, diligence, honesty and responsibility; and ten competencies include three general competecies (autonomy and independent learning, communication and collaboration, problem-solving and creativity), as also seven specific competencies in languages, mathematics, scientific, technology, computer science, aesthetics and physical competency.

The spirit of Global citizenship education has also been gradually actualized in Vietnamese educational practice. The Ministry of Education and Training issued Decision to Approve the Adjustment and Supplementation of the Scheme on Teaching and Learning Foreign Languages in the National Education System from 2017 to 2025; and directed educational institutions to deploy solutions to improve the quality of foreign language teaching under the direction of standardization and practicality at all educational levels, with the formulation and promulgation of the 6-level foreign language competence framework of Vietnam. At high school level, the 10-years pilot English Program was issued in the direction of developing communication skills in English. Other foreign languages were also in the 7years program. In the school year 2017-2018, the10-years English program was implemented in 63 provinces and cities.

Especially, Global Citizenship Education has been implemented in the Vinschool educational system from the beginning of the 2019-2020 school year, with the mission to provide learners with skills to become a Global citizen in the new era. Global citizenship education has gradually helped Vinser to extend knowledge and skills to serve the community. Students access to Global citizenship education with different topics: Poverty and hunger reduction, Climate change, Equality and reduction of inequality, Sustainable economic development. These topics were approached through 5 Prisms: Global Mindedness, System Thinking, Information Criticality, Innovation and Collaboration.

In the new general educational curriculum, the spirit of Global citizenship education is strongly reflected in the subject of civic education. The new Civic Education program has achieved progresses, compared to the current program: 1/ Combining tradition and modernity in ethical education; 2/ Paying more attention to teaching practical life skills, for example: preventing accident and injury, child abuse, domestic violence and school violence, dealing with dangerous situations, adapting to changes, ...; 3/ Replacing academic political economic knowledge with practical economic education such as consumption activities (savings, money management, smart consumption ...), the operation of the economy (market and market mechanisms, competition, inflation, unemployment ...), state economic activities (budgets and taxes, labor-employment market, insurance and social security), production and business activities; 4/ Eliminating abstract knowledge of philosophy and ethics, supplementing practical law education (Labor Law, Civil Law, Criminal Law, Business Law ...), paying special attention to Human Rights Education from primary to high school at, from low level to high level, from the United Nations Convention on the Rights of the Child to conventions on civil rights and human rights. The program is designed to be age-appropriate, practical and vocation-oriented for students after high school program.

\section{Innovation in higher education}

The mission of higher education is to train high-quality human resources for the labor market in the future. Clearly identifying the challenges that Vietnamese students have to face in IR4.0, we are aware that the target of Global citizens training is increasingly important for higher education. International integration and internationalization of higher education are 
indispensable, which determines the existence and development of universities. Vietnamese students need to become Global citizens by equipping themselves with necessary skills to be able to work anywhere in the world. Internationalization of higher education plays an important role in improving the quality of higher education, trains Global citizens and attracts international students to study in Vietnam. Promoting scientific research and attractingscientists around the world to Vietnam to work and research helps enhance Vietnam's educational position in the world, which is essential.

Vietnam has issued many guidelines and policies on international cooperative education. Typically, the national qualification framework of Vietnam is in line with the European qualification framework and suitable for approximately $70 \%$ of the qualification framework of countries in the world. The law on amendments to law on higher education in 2018 is a breakthrough which aims at improving the autonomy of universities including international cooperation, and at the same time, facilitates foreign higher education institutions to establish branches in Vietnam. Decree 86/2018 on foreign cooperation and investment in education seems to be much more open. In particular, Vietnamese Government has permitted online joint training program with foreign universities.

Higher education in Vietnam aims to educate Global citizens in the following aspects:

1. Developing a common educational philosophy for Vietnam education in general as well as the philosophy for each university and educational institutions in particular, both of which are consistent with the trend of integration into the general flow of international education.

2. Innovating higher education management thinking: Overcoming the imposed and subsidized management thinking in higher education, creating conditions for higher education institutions to be more autonomous in their activities such as: changing the way of enrollment, deciding on admission standards and taking responsibility for learners by training reputation; forming various university training models, strictly controlling the output of each training institution to ensure the general quality .etc.

3. Renewing the program content according to the direction of international integration: regularly updating modern knowledge; flexibly using domestic and foreign textbooks and learning materials; Teaching content is suitable with practical requirements of the profession chosen.

4. Using a variety of teaching methods based on the learner-centered principle,reducing in-class cognitive load so that learners have time for self-study; regularly checking and evaluating objectively and closely to ensure the effectiveness of teaching and learning.

5. Strengthening international research and publication activities, internationalizing scientific evaluation criteria and professional activities at higher education institutions; Adopting policies to encourage scientists to research and actively publish research results in international scientific publications.

These above-mentioned solutions aim to enhance the integration of Vietnamese higher education into the international environment, contributing to training GCs in the IR4.0 


\section{CONCLUSION}

IR4.0 took place as aninevitable rule during the development of human history, opening up a number of opportunities and challenges for all countries in the world. We have no choice but to actively participate in that revolution unless we want to be left behind. Vietnam has been a developing country with many difficulties and challenges. In order to keep pace with the IR4.0, each individual needs to be deeply aware of his/her own responsibilities. Everyone should be educated and educate themselves to become Global citizens who are capable of seizing opportunities and overcoming challenges, redrawing their national position on the world map in the new age.

\section{References}

Dien Bui Thi (2019), An approach to global citizenship education in Literature, Vietnam Journal of Educational Sciences, No. 22, October.

Duc Tran Khanh (2019), The Fourth Industrial Revolution and the role, mission of universities of science and technology in the cause of training high-quality human resources, Vietnam Journal of Educational Sciences, No. 21, September

Ha Nguyen Thi Viet (2019), Global Citizenship Education in Civic Education in Secondary schools (New General Education Curriculumn), Vietnam Journal of Educational Sciences, No. 21, September

Mannion, G., Biesta, G., Priestley, M., \& Ross, H. (2011). The global dimension in education and education for global citizenship: Genealogy and critique. Globalisation, Societies and Education, 9(3-4), 443-456.

Ministry of Education and Training (2018), General education curriculum, Issued together with Circular No. 32/2018 / TT-BGDDT dated December 26, 2018 of the Minister of Education and Training

Nga Nguyen Tuyet, Lien Nguyen Hong (2019), Global Citizenship Education through History and Geography in Primary schools, Vietnam Journal of Educational Sciences, No. 21, September

Puncreobutr, V. (2016). Education 4.0: New challenge of learning. St. Theresa Journal of Humanities and Social Sciences, 2(2).

Vi Nguyen Huy, Giao Nguyen Long (2019), Adaptation of Vietnamese education to the impact of the Industrial Revolution 4.0, Vietnam Journal of Educational Sciences, No. 21, September

Vietnamese Communist Party (2013), Resolution 29-NQ/TW dated $4^{\text {th }}$ November 2013 issued by the Xith Vietnamese Communist Party on the 8th Congress about renovating basically and holistically education and training.

Yanzi, H., Hidayat, O. T., Mentari, A., \& Budimansyah, D. (2019). Global Citizens Awareness through Digital Literacy in the Fourth Industrial Revolution: A Review of the Literature. Series: Advances in Social Science, Education and Humanities Research, 317(13), 65-69.

www.weforum.org/agenda/2016/01/the-fourth-industrial-revolution-what-it-means-and-how-to-respond. https://vi.wikipedia.org/wiki/C\%C3\%B4ng_d\%C3\%A2n_to\%C3\%A0n_c\%E1\%BA\%A7u https://www.globalcitizen.org/en/about/who-we-are/ https://en.unesco.org/themes/gced https://www.oxfam.org.uk/education/who-we-are/what-is-global-citizenship 